\title{
BIOLOGICALLY ACTIVE COMPOUNDS IN THE SEA
}

\author{
By R. Johnston \\ Marine Laboratory, Aberdeen
}

\section{INTRODUCTION}

It is becoming recognized that metabolites released into aquatic and other environments may have vital significance for associated communities. For the particular habitat of the sea, Lucas (1938) indicated tentatively some of the possibilities and later (1947, I949) reviewed some of the extensive evidence which provided support for a new concept of 'non-predatory' inter-relationships. External metabolites ('ectocrines') formed by some organisms were envisaged as favouring or hindering the growth of other members of the community, their effects varying according to their concentrations. Although a few might extend their effects in relatively large concentrations, many (perhaps the most important) were regarded as effective at extreme dilution. Metabolites could conceivably neutralize the growth-inhibiting or growthpromoting effects of other substances, presumably including other metabolites. The production and persistence of metabolites in a body of sea water imposed a 'biological history' on the water and provided a basis for ecological 'succession'. The general evidence of 'succession', like that implying 'animal exclusion' (Hardy, I935), almost demanded such a concept in support.

The concept of 'non-predatory' relationships drew support from a wide variety of biological observations but, until recently, little biochemical work has been carried out to detect or identify metabolites. The early experiments (e.g. Allen \& Nelson, I9I0), showing the importance of organic matter for establishing successful cultures, led logically to Harvey's demonstration (I933 and later) of the necessity for accessory factors in the growth of some marine diatoms, while other workers showed the significance of pro- and antibiotic substances in the culture of algae and other micro-organisms (e.g. Lefevre et al., I952). A few workers (e.g. Harvey, I939; Matsudiara, I939) had demonstrated differences in sea waters as culture media, and Hutchinson (I943), for example, produced evidence of a free vitamin (thiamin) in lake water. Recently a number of prominent contributions have been made by the workers at the Haskins Laboratories (New York) who have investigated with great precision the nutrition of a few marine and freshwater micro-organisms. Their work is demonstrating interdependencies such as: '(I) the interchange of growth factors; (2) the lowering of inhibitory concentrations of several major mineral 
nutrients, especially phosphate; and (3) the preferential utilization of minerals, including trace metals, [which] may condition waters, bringing their concentrations into the optimal zones for succeeding forms'. They consider that the practical aim, 'to predict algal successions and blooms - may be achieved through a comprehensive knowledge of vitamin cycles as well as mineral cycles. An immediate problem is to trace the thiamin and cobalamin cycles' (Provasoli \& Pintner, 1953, p. 849).

Meanwhile, Wilson (I932 and later) had observed that some polychaete larvae would only settle on limited types of sand which were almost certainly associated with other and perhaps specific forms of life. In another series of experiments (Wilson, I95I; Wilson \& Armstrong, 1952, I954) he demonstrated that the eggs and larvae of the sea urchin (and two species of marine worms studied less intensively) would grow more satisfactorily in water from the Celtic Sea than in English Channel water. It is significant that these waters can be distinguished by the characteristic species of Sagitta so that Wilson's experiments link directly with Russell's demonstration (I935) of the importance of 'western' water for good productivity in the English Channel. The general idea of sea-water characterization by chaetognath indicator species was developed for more extensive sea areas by Fraser (1937, 1939) and some postulates were made with regard to possible operative factors (Fraser, I952).

Although in a broad sense closely related to their hydrographic environment, it is now familiar knowledge that planktonic communities may sometimes be sharply distinguished even within a water mass which is homogeneous with regard to all the usual hydrographic characteristics, including nutrients. Not only may hydrographic and nutrient contents of natural waters be significant, and inorganic micro-constituents at a more subtle level, but also the organic compounds present as the result of past and present metabolic processes. Indeed, in so far as final productivity depends on the success of photosynthetic micro-organisms, any demonstration of the dependence of these organisms on external metabolites points indirectly, if not directly, to the significance of such metabolites for the rest of the community.

It may even be legitimate to speculate further on the possible value of such work. The sensitivity of some micro-organisms to certain metabolites has been shown to be extremely high, their productivity being entirely dependent on the availability of these metabolites, whatever the grosser nutrients available (see, for example, Hamilton, Hutner \& Provasoli, I952). The possibility arises, therefore, of initiating a chain reaction of biological events ('succession') by adding to natural waters metabolites likely to encourage a desirable sequence and to suppress undesirable types. Since no additional nutrients are involved, and since the quantities of the metabolites may be relatively very small, this possibility may lead to more practical methods of controlling some aspects of aquatic life than have so far been suggested. 
Thus the study of biologically active organic substances ${ }^{1}$ in the sea is at least indirectly relevant to fishery problems. In time, some compounds may be shown to be directly relevant-perhaps by favouring or hindering the development of fish eggs or larvae, or even affecting the adult life of shellfish and true fish. One hint may be found in the observations of Collier, Ray, Magnitzky \& Bell (I953) that the active feeding of oysters is related to the concentration in the sea water of certain organic substances, which respond to the $N$-ethyl carbazole test for carbohydrates. Perhaps another lies in the results of fish-behaviour studies. It has been suggested that salmon may be able to distinguish the products of one organism from another even at great dilutions and perhaps thereby the waters of one stream from others (see, for example, Lissmann's review, I954). The requirements which must be fulfilled to satisfy the theory that fish discriminate 'home' waters by perception of special characteristic chemical constituents have been described by Hasler \& Wisby (I95I). They have tracked down the characteristic odour in one instance to a volatile aromatic substance.

\section{Previous Organic Analyses of Sea Water}

Much of the early work on the analysis of organic matter in the sea relied on combustion or powerful oxidizing agents (Bond, I933; Krogh \& Keys, I934) to give an estimate of the total carbon present, and gave no clue regarding the nature of the compounds involved. A most extensive review of analyses of marine organisms, including plankton, from the earliest records to 1944 has been prepared by Vinogradov (I953). The analyses are chiefly concerned with moisture content, ash and assays of $\mathrm{C}, \mathrm{H}, \mathrm{N}, \mathrm{P}$ and many other elements. Recently, the particulate matter (organic and inorganic) in sea water has been studied and partly analysed by Armstrong \& Atkins (1950) and also by Fox, Oppenheimer \& Kittredge (I953). The inanimate organic matter in the sea, according to the most recent estimate (Fox et al., I953), occurs to the extent of approximately $60 \%$ as particulate matter and about $40 \%$ as dissolved substances.

The separation and analysis of dissolved organic matter isolated from sea water has seldom been reported. Wangersky (1952) isolated by dialysis what was considered to be a rhamnose-containing polysaccharide which affected the feeding of oysters (Collier et al., 1950).

It is perhaps reasonable to consider as potentially soluble some of the organic compounds found internally in marine plants and animals. An up to date and comprehensive review and bibliography has been prepared by Black (I954) of the organic chemical analysis of many of the constituents of brown, red and green algae.

\footnotetext{
${ }^{1}$ When the organic matter is isolated from a sample of sea water whose biological history will normally be unknown, it is more accurate to describe any active compounds simply as biologically active (to organism ' $\mathrm{X}$ ') than to describe them as 'ectocrines' which may imply knowledge of the original sources which is not yet available.
} 


\section{WORK AT ABERDEEN}

With such possibilities in mind, work was begun at Aberdeen to see whether natural waters could be distinguished by their organic content and, specifically, whether the organic content could be shown to have variable significance for representative marine micro-organisms. This paper gives a brief outline of the first results. It will have served its purpose if it provokes discussion, perhaps some pooling of ideas, and stimulates further work on the biological and biochemical sides, for assuredly the two must go together.

Possible lines of advance in the study of organic matter in the sea may lie in (a) direct organic analysis of extracts from large amounts of sea water, (b) intensive assay of natural and enriched sea waters with specific microorganisms, and $(c)$ isolation of metabolites from pure mass cultures. Each of these possibilities might make an important contribution to marine science but the total work required would be very large. A more incisive attack, which might enable important features to be detected relatively quickly, demands a speedy method of isolating organic matter from relatively small samples of filtered sea water, followed by analysis of the extract and biological testing of some of the components. Final details of the method to be adopted are not yet settled, but the following paragraphs describe its evolution and the results to date.

\section{Methods of Isolation}

The earliest experiments were straightforward applications of normal methods of isolating organic compounds to the separation of dissolved organic matter from sea water. In each experiment the sea-water sample was first passed through a I $\mu$ filter soon after collection to remove detritus, plankton and, as far as possible, all the nanoplankton. Various methods of isolation were tried and the results obtained are summarized below.

(I) Evaporation and extraction. Sea water was evaporated at $30-40^{\circ} \mathrm{C}$. under reduced pressure and portions of the salt residue extracted with various organic liquids. Most common solvents, e.g. alcohol, acetone, ether and, to a lesser extent, chloroform, dissolved troublesome amounts of salts in addition to any organic matter. Benzene gave least salt contamination but only a very small amount of extract. Handling of the original hygroscopic mass of salts was difficult and complete extraction was laborious.

(2) Solvent extraction. Extraction with organic liquids immiscible with sea water was a convenient and rapid method of isolating some of the fatty, waxy and highly coloured substances. Only solvents which did not dissolve appreciable amounts of salts were suitable, such as benzene.

(3) Dialysis. Sea water was dialysed against tap water to yield on evaporation organic residues of high molecular weight. The method demands the handling of fairly large volumes of liquid in order to obtain a reasonable yield but is perhaps one of the most useful, although only applicable to a restricted range of organic compounds.

(4) Ion-exchange treatment. Direct ion-exchange treatment of sea water proved quite unsatisfactory owing to the high salt concentration. The process can be useful, however, for removing final traces of salts from any type of extract. 
(5) Adsorption. Many substances can be used to adsorb some part of the organic (and at the same time some inorganic) matter from sea water. Carbon, alumina, cotton-wool and cellulose powder were tried. The method is simple, fairly rapid, and not very selective in the types of organic compounds removed. Some results for carbon extracts are described later.

(6) Electrodialysis. The most recent separations were by this method, which in theory should yield the total organic matter more or less unchanged and free from salts. Supplies are becoming available of ion-exchange membranes which are impermeable to organic substances except perhaps the most mobile fatty acid ions, e.g. formate, acetate. Objections to the use of membranes such as parchment or cellophane, which permit the passage out of the solution of, for example, amino-acids and neutral organic compounds of low molecular weight are thus overcome. The method is convenient but slow, and further development of a suitable type of apparatus is required. Multimembrane types have the particular advantage of minimizing temperature breakdown and electrolytic reduction or oxidation of sensitive organic materials.

\section{Qualitative Analysis of Organic Extracts}

Many methods were attempted. In general, direct organic analysis, spot tests, micro-reactions and paper chromatograms sprayed with selective reagents yielded relatively indecisive results on the gross extracts, and also after attempted fractionation, perhaps because separations were not complete. However, several clues were obtained.

Among the most common components of the carbon extracts were (I) an insoluble white substance similar to that described by Wilson \& Armstrong (I952, p. 338), (2) coloured material, possibly carotenoid, soluble in benzene, petroleum ethers, etc., (3) a fairly large proportion of brownish waxy or fatty matter, and (4) yellowish orange matter with a bright blue fluorescence in ultra-violet light (probably related to the 'gelbstoff' of Kalle, I949). A number of other components were detected by paper chromatography and examination in ultra-violet light but could not be satisfactorily separated by preliminary attempts using column chromatography.

\section{Empirical Organic Analysis of Sea Water Samples}

Salt-free carbon extracts from filtered samples of sea water are readily compared by preparing paper chromatograms of portions of the extracts (see, for example, Balston \& Talbot, I952, for general technical details).

Sea water (2 1.) is shaken with activated carbon (c. Io g) and allowed to stand. Most of the liquid can then be sucked or siphoned off, the carbon recovered on a filter and washed with distilled water until chloride-free. A cold extraction process, using alcohol followed by an alcohol-benzene mixture, has been used to recover the organic matter from the carbon.

Because of variations in the adsorptive powers of various carbons and in their extractable impurities, it is essential to standardize the technique by 
using only one type of carbon and by including carbon blanks. These blanks consist of carbon, shaken with sample volumes of 3.5\% saline solution, and washed and extracted in the same way as the sea-water samples.

When chromatograms of the extracts and the carbon blanks were compared by ultra-violet light, different patterns and numbers of spots were seen. Provided interfering inorganic matter has been removed, these spots represent different organic components of the sea-water samples. Unknown proportions of only those compounds which are adsorbed by carbon from sea water are represented in the extract, however, and not necessarily all the soluble organic matter present.

Any suitable combination of adsorbent, solvent or paper chromatogram technique can be tried. The method yields comparative organic chemical analyses of extracts from small sea-water samples with minimum effort. For known constituents it could be developed to give approximate quantitative analysis by colorimetric methods or for bio-assay by plating or culture techniques. Especially in the case of microbiological assay it would be necessary to ensure adequate control measures to eliminate spurious effects arising from impurities in the activated carbon and in the solvents used.

\section{Biological Effects of Some Organic Isolates}

Since the preliminary qualitative organic analysis of such extracts had proved unrewarding, it was important to decide whether further attempts were worth while. The immediate value of the study of organic matter must be dependent largely on some components proving to be of biological interest, possessing, for example, growth-promoting or growth-inhibiting properties. It was not possible to test biological activity in a wide range of ways at a number of different concentrations because of the small quantities of each fraction then available, but it was felt that the responses of some common marine phytoplankton species might provide indications of biological activity of possible significance for fisheries.

An artificial basal medium was prepared according to formulae devised by Provasoli \& Pintner (1953, p. 842). The plankton cultures were kindly supplied by Dr Mary Parke of the Laboratory at Plymouth. Growth was assessed by measuring change in optical density of small cultures in closed tubes. A list of the eleven types which were grown in sixteen different media is given in Table I. The various additions to the basal inorganic medium are listed in Table II. Usually the organic extract was obtained from sea water by means of adsorption on carbon. In assessing the subsequent growth of cultures, differences in optical density of $>8$ units are significant at the $90 \%$ level; $>$ Io units at the $95 \%$ level.

The algae reacted to several of the fractions, exhibiting both increased and decreased growth, as compared with controls. Further (and perhaps different) instances of these effects would probably have been observed 


\section{TABLE I}

Number of experiments with values

Medium no. (see Table II)

\begin{tabular}{|c|c|c|c|c|c|c|c|c|c|c|c|c|c|c|c|c|}
\hline Culture used & I & 2 & 3 & 4 & 5 & 6 & 7 & 8 & 9 & IO & II & I2 & I3 & I4 & I5 & I6 \\
\hline Skeletonema costatum (Grev.) Cleve & -12 & 5 & -5 & 0 & 7 & o & -13 & 6 & 3 & 9 & - Io & 5 & -7 & -8 & 7 & 3 \\
\hline Mixed culture (Ab & I4 & 29 & I & 0 & 35 & -3 & & 2 & & 12 & - & 2 & 2 & - & -3 & 9 \\
\hline Thala & 3 & -3 & - II & 9 & Io & 12 & -1 & 3 & 6 & IO & - & I & 5 & 2 & 4 & 5 \\
\hline Cleve & 5 & 3 & 2 & 2 & -3 & -5 & 12 & -1 & Io & -6 & -9 & -3 & 9 & 6 & -2 & $-I$ \\
\hline $\begin{array}{l}\text { ix frauenfeldii Grun. } \\
\text { Grun. }\end{array}$ & -5 & 2 & I2 & -4 & Io & I 7 & -2 & 30 & -8 & 3 & 13 & II & -8 & 6 & -6 & $?$ \\
\hline Prorocen & 4 & 5 & -4 & I & 8 & -9 & I8 & 24 & -10 & - Io & & I & $-I$ & 7 & 2 & $-I$ \\
\hline unaliella $\mathrm{s}$ & $5 \mathrm{I}$ & $6 \mathrm{I}$ & 93 & 96 & 47 & 73 & 57 & 254 & I30 & 57 & $5 c$ & 176 & 65 & 59 & II 6 & 68 \\
\hline ochrysis galbana Parke & 0 & 40 & 9 & $-\mathrm{I} 2$ & I3 & -4 & 5 & 39 & -4 & I5 & 17 & 2 & 4 & IO & - II & 4 \\
\hline
\end{tabular}

$\geqslant$ Io Others

$\overbrace{+\quad-}$

Successful cultures

Unsuccessful cultures

Little changet

$\begin{array}{llllllllllllllll}2 & 4 & 3 & 2 & 7 & 3 & 3 & 9 & 4 & 5 & 4 & 5 & 3 & 2 & 2 & 3 \\ \mathrm{I} & 0 & \mathrm{I} & \mathrm{I} & 0 & \mathrm{I} & 2 & 0 & \mathrm{I} & \mathrm{I} & 2 & 0 & 0 & \mathrm{I} & \mathrm{I} & 0 \\ 8 & 7 & 7 & 8 & 4 & 7 & 6 & 2 & 6 & 5 & 5 & 6 & 8 & 8 & 8 & 8\end{array}$

Values in the table represent changes in optical density $\left(\log I_{0} / I \times \mathrm{IO}^{3}\right)$ between Ist (IO. viii. 53) and I8th day (28. viii. 53 ), for $5 \mathrm{ml}$. cultures in I cm diameter tubes. Light filter for Spekker, Ilford 601. Temperature range $15 \cdot 4^{-15} \cdot 7^{\circ} \mathrm{C}$. Light intensity $c .2200$ lux, continuous. Media adjusted to initial pH $8 \cdot 0$. * Chaetoceros ceratosporus (or gracilis) and a Chlorococcus sp.

† Includes unsuccessful cultures of colourless species. 
by testing a range of concentrations. One particular fraction was found to promote greater growth in nine of the eleven species tested. Other fractions affected smaller numbers of species favourably or unfavourably. The algal cultures used, although species-pure, were not bacteria-free, so that the observed changes in optical density of the cultures may not refer directly to the original medium supplied but to a medium modified by bacterial metabolism. Large-scale bacterial proliferation could also directly alter the optical density of the cultures. To what extent such effects complicate the assessment

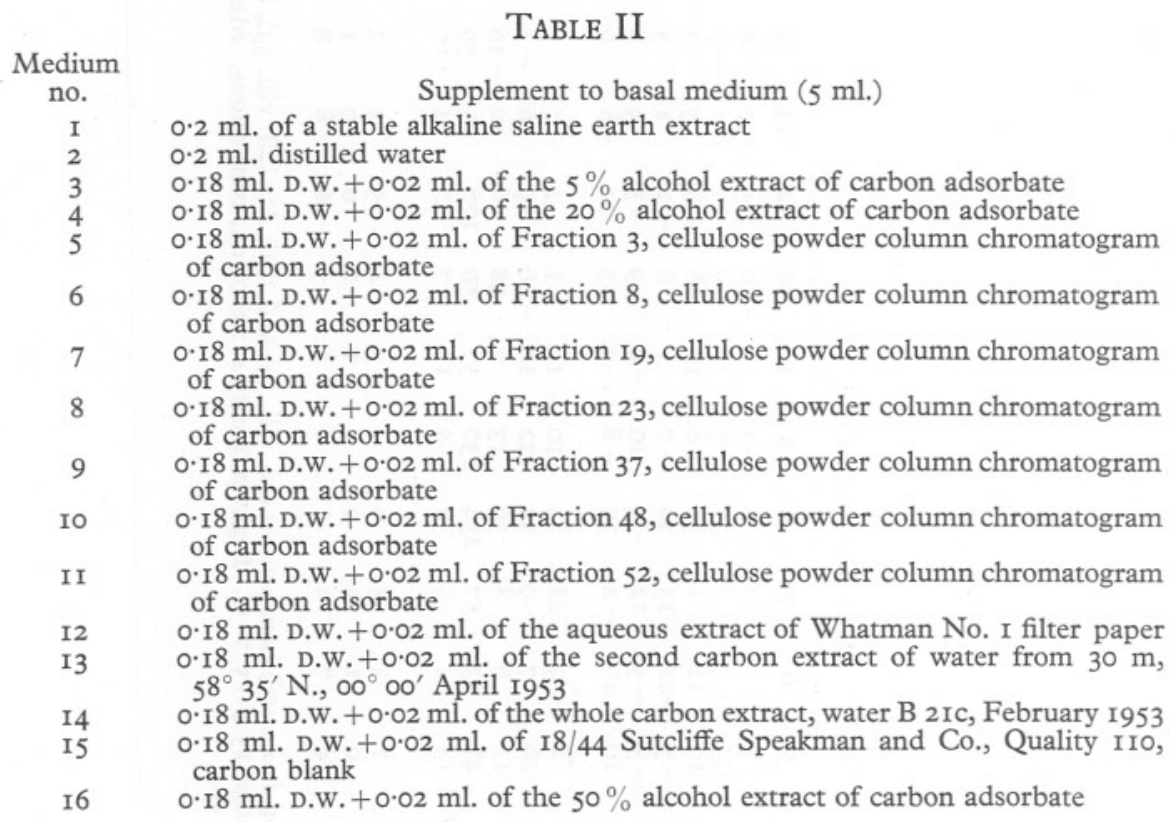

of the biological activity on the algae is not known at present, although examination of the cultures at the end of the experiment showed no obvious signs of bacterial colonies. Many of the cultures persisted for several months after the completion of the experiments. In any event, although of fundamental interest, the distinction is of less immediate importance, since most, if not all, algae normally grow in association with bacteria, from which they may well acquire some accessory nutrients.

It is difficult to relate the concentrations of organic isolates in the culture media to those of the appropriate fractions in the original sea-water samples since so many losses inevitably occur during isolation and fractionation. The in vitro concentrations used probably ranged between 2 and 40 times those occurring naturally, but it should be stressed that this is a very approximate reckoning, and these estimates may be too high. 


\section{Future Lines of Research}

This preliminary work suggests that a method based on $(a)$ isolation of organic matter by electrodialysis using ion-exchange membranes, (b) separation by paper chromatography, and (c) biological testing using a number of organisms, should meet the requirements of sensitivity and selectivity. An examination of the complete organic matter in solution is still reasonably economic in labour.

It is hoped that, in this way, it may be possible to 'label' water samples (and consequently the water masses from which they derive) somewhat grossly according to (I) the number and chromatographic position of some organic compounds, and (2) the nature of some of their biological effects-even before it is possible to indicate the chemical nature of the organic differences concerned. Such results should be of immediate help in the interpretation of the ecological situation, whilst the observed biological differences should give pointers to the sections of the extracts most deserving chemical analyses. It may conceivably be possible to apply the results to fish behaviour and/or development.

Although the main chemical effort will be directed to this end, it is not intended to omit analyses of the dissolved organic matter. Preparations are in hand for continuous de-salting of sea water in fairly large quantities by ionexchange electrodialysis. Work already done can be utilized to construct a more effective course of preliminary separation, and automatic fractionation apparatus has recently been obtained which will facilitate chromatography. Individual fractions can then be tested for biological activity and facilities are available for ultra-violet and infra-red spectroscopic analysis of interesting components. It may be possible, using this knowledge and experience, to obtain by a shorter method sufficient of the interesting fractions to permit fuller qualitative organic micro-analysis.

\section{SUMMARY}

The concept of external metabolites in the sea, which has received support from biological investigations, invites chemical corroboration which, until recently, has not been forthcoming. Separations of organic matter from filtered sea water using a variety of methods are reported and a preliminary assessment made. Organic residues obtained from different open sea sources by adsorption on carbon give rise to different paper chromatogram patterns. Certain organic components of a carbon adsorbate contain substances which affect the growth of a number of marine phytoplankton organisms. Further research is planned employing methods of isolation and chromatography of the dissolved organic matter from different sea waters and the assessment of biological activity of certain fractions by means of common marine organisms. Some aspects of the significance of biologically active compounds in the sea are mentioned. 


\section{REFERENCES}

Allen, E. J. \& Nelson, W. E., I9I0. On the artificial culture of marine plankton organisms. F. Mar. biol. Ass. U.K., Vol. 8, pp. 42I-74.

Armstrong, F. A. J. \& Atkins, W. R. G., I950. The suspended matter of sea water. F. Mar. biol. Ass. U.K., Vol. 29, pp. 139-43.

Balston, J. N. \& Talbot, B. E., I952. A Guide to Filter Paper and Cellulose Powder Chromatography, I45 pp. London: Angel; Maidstone: Balston.

BlACK, W. A. P., I954. Constituents of the marine algae. Rep. Progr. Chem., Vol. 50 (I953), pp. 322-35.

Bond, R. M., I933. A contribution to the study of the natural food cycle in aquatic environments. Bull. Bingham oceanogr. Coll., Vol. 4, Art. 4, 89 pp.

COLlieR, A., RAY, S. M. \& MAGNITZKY, A. W., I950. A preliminary note on naturally occurring substances in sea-water affecting the feeding of oysters. Science, Vol. III, pp. I5I-2.

Collier, A., Ray, S. M., Magnitzky, A. W. \& Bell, J. O., I953. Effect of dissolved organic substances on oysters. Fish. Bull. U.S., Vol. 54, pp. 167-85.

Fox, D. L., OpPenHeimer, C. H. \& KitTredGe, T. S., I953. Microfiltration in oceanographic research. II. F. Mar. Res., Vol. I2, pp. 233-43.

FRASER, J. H., 1937. The distribution of Chaetognatha in Scottish waters during 1936, with notes on the Scottish indicator species. F. Cons. int. Explor. Mer, Vol. I2, pp. $3 \mathrm{II}-20$.

- 1939. The distribution of Chaetognatha in Scottish waters in 1937. F. Cons. int. Explor. Mer, Vol. I4, pp. 25-34.

- I952. The Chaetognatha and other zooplankton of the Scottish area and their value as biological indicators of hydrographical conditions. Mar. Res. Scot., I952, No. 2, 52 pp.

Hamilton, L. D., Hutner, S. H. \& Provasoli, L., I952. The use of Protozoa in analysis. Analyst, Vol. 77, pp. 6r8-25.

Hardy, A. C., I935, in Hardy, A. C. \& Gunther, E. R., I935. The plankton of South Georgia whaling grounds and adjacent waters I926-I927. Discovery Rep., Vol. I I, pp. 300-22.

Harvey, H. W., I933. On the rate of diatom growth. F. Mar. biol. Ass. U.K., Vol. I9, pp. $253-76$.

- 1939. Substances controlling the growth of a diatom. F. Mar. biol. Ass. U.K., Vol. 23, pp. 499-520.

HAsleR, A. D. \& Wisby, W. J., I95I. Discrimination of stream odors by fishes and its relation to parent stream behavior. Amer. Nat., Vol. 85, pp. 223-38.

Hutchinson, G. E., I943. Thiamin in lake waters and aquatic organisms. Arch. Biochem., Vol. 2, pp. I43-50.

Kalle, K., 1949. Fluoreszenz und Gelbstoff im Bottnischen und Finnischen Meerbusen. Dtsch. hydrogr. Z., Bd. 2, pp. II 7-24.

KRoGH, A. \& KeYs, A., I934. Methods for the determination of dissolved organic carbon and nitrogen in sea water. Biol. Bull., Woods Hole, Vol. 67, pp. 132-44.

LefeVre, M., Jakob, H. \& Nisbet, M. I952. Auto- et hétéroantagonisme chez les algues d'eau douce. Ann. Sta. cent. Hydrobiol. appl., T. 4, I97 pp.

Lissmann, H. W., I954. Direction finding in fish. Advanc. Sci., Vol. II, pp. 69-7I.

LUCAS, C. E., 1938. Some aspects of integration in planktonic communities. F. Cons. int. Explor. Mer, Vol. I3, pp. 309-22.

—_ 1947. The ecological effects of external metabolites. Biol. Rev., Vol. 22, pp. 270-95.

- 1949. External metabolites and ecological adaptation. Symp. Soc. exp. Biol., No. 3, pp. 336-56. 
Matsudiara, T., I939. The physiological property of sea water considered from the effect upon the growth of diatoms, with special reference to its vertical and seasonal changes. Bull. Fap. Soc. sci. Fish., Vol. 8, pp. 187-93.

Provasoli, L. \& PINTNER, L. J., I953. Ecological implications of in vitro nutritional requirements of algal flagellates. Ann. N.Y. Acad. Sci., Vol. 56, pp. 839-5I.

RUSSELL, F. S., I935. On the value of certain plankton animals as indicators of water movements in the English Channel and North Sea. F. Mar. biol. Ass. U.K., Vol. 20, pp. 309-32.

VINogradov, A. P., I953. The elementary chemical composition of marine organisms; trans. by Julia Efron and Jane K. Setlow. Mem. Sears Fdn Mar. Res., No. 2, $647 \mathrm{pp}$.

WANGERSKY, P., I952. The isolation of ascorbic acid and rhamnosides from sea-water. Science, Vol. II5, p. 685.

WILson, D. P., I932. On the Mitraria larva of Owenia fusiformis Delle Chiaje. Phil. Trans., B, Vol. 221, pp. 23I-334.

_ I951. A biological difference between natural sea waters. F. Mar. biol. Ass. U.K., Vol. 30, pp. I-20.

Wilson, D. P. \& Armstrong, F. A. J., I952. Further experiments on biological differences between natural sea waters. F. Mar. biol. Ass. U.K., Vol. 31, pp. 335-49.

_ _ 1954. Biological differences between sea waters; experiments in 1953. F. Mar. biol. Ass. U.K., Vol. 33, pp. 347-60. 